\title{
A Review on Aspergillosis in Poultry
}

Genene Girma ${ }^{1}$, Mengestie Abebaw ${ }^{1}$, Mebrie Zemene ${ }^{1 *}$, Yergashewa Mamuye ${ }^{1}$ and Gashaw Getaneh ${ }^{2}$

${ }^{1}$ Faculty of Veterinary Medicine, Department of Veterinary Pharmacy, University of Gondar, Gondar, Ethiopia

${ }^{2}$ Faculty of Veterinary Medicine, Department of Biomedical Science, University of Gondar, Gondar, Ethiopia

\begin{abstract}
Aspergillosis is a respiratory disease of chicken, turkey, humans and other mammals and less frequently ducks, pigeon, geese and other wild and domestic birds. It is cuased by a fungal species under the genus Aspergillus. In chickens and turkey, the disease may be endemic on some farm. In wild birds, it appears too sporadic, frequently affecting only an individual bird. It is usually seen in birds of 7-40 days old. Aspergillus spp are ubiquitous and the disease is found where ever environmental condition is favorable for growth. Aspergillus fumigatus is frequently isolated in affected bird. Infection occurs by inhalation of spores. The disease has two forms, acute and chronic form. The acute form occurs when large amount of spores are ingested by the bird, where as, the chronic form affects birds under immune suppression. The clinical signs are non-specific and a variety of diagnostic procedures are required for the diagnosis of aspergillosis in poultry, of which culturing is very important. Treatment of aspergillosis is not effective and prevention is the best way of controlling the disease. Good managemental practices such as sanitation, avoiding wet litter or soil and moldy or dusty feeds, provididing adequate ventilation, and disinfecting feed and water lines should be implemented to prevent and control the disease.
\end{abstract}

Keywords: Aspergillosis; Aspergillus fumigatus; Pevenetion

\section{Introduction}

Aspergillosis is non-contagious disease of avian. It is cuased by a fungal species under the genus Aspergillus. The disease occurs under immune compromised situations of the host or when the bird is exposed to an overwhelming number of spores. Stress is the main predisposing factor for the development of the disease [1]. It is a common mismanagement problem in commercial and back yard poultry. The disease primarily affects lower respiratory system [2].

Aspergillus spp can penetrate egg shell and infect the embryo. The infected embryo may die or hatch with well developed lesion. If infected eggs are broken, large numbers of spores are released, which contaminate the hatchery equipment [3]. Aspergillosis can be acute or chronic form. Acute aspergillosis generally occurs in young birds and resulting in high morbidity and mortality. The chronic form is sporadic and it causes lesser mortality and generally affects older birds, especially a compromised immune system due to poor husbandry condition [2].

Poor sanitation in the house as well as food contamination promotes fungal growth. Poor ventilation in conjunction with these factor increase the possibility of invassion and infection of birds' respiratory system by air borne spore [2]. Mycotoxins are toxic secondary metabolites produced by organisms of the fungus. Aflatoxin is a type of mycotoxins produced by Aspergillus flavus and Aspergillus parasiticus and ochratoxin is produced by Aspergillus ochraecus that affect poultry when they consume contaminated food [4-6]. Therefore, the objectives of this paper are to highlight about poultry Aspergillosis (Table 1).

\section{Etiology}

Aspergillosis in poultry is cuased by a fungal species under the genus Aspergillus. Organisms cultured from affected organ in decreasing frequency are: Aspergillus fumigates, A. flavus, A. niger, A. glaucus and A. terreus. From these spp, A. fumigatus is a common cause of the disease. These organisms are common soil saprophytes which grow on organic matter in warm $\left(>25^{\circ} \mathrm{C}\right)$ and also humid environment, and damaged egg in hatchery $[7,8]$.

Most of the species under the genus Aspergillus are classified as fungi imperfect (asexual reproduction) but the perfect state has been found in Aspergillus nidulans that can be reproduced by ascospores. When grow start hyphae, together forming mycelia. Vegetative mycelia consists of superficial hyphae and hyphae on the surface are aerial mycelia. This structure produce conidiophore, these are formed in foot cells and end in a vesicle, in this stricter grow one line of phyalides or one line of mutulae and over this stricter one line of phyalides that produce a chain of conidia or spores. Conidia are uni or multi nucleated but always single celled [6].

The function of the conidia is dissemination of the fungus. Aspergillus is useable as a food in many different substances because of the number of enzyme that it can produce. The two main requirement of substance for fungal growth are organic matter and moisture, if both factors are present the fungus can grow in almost any substance. The shape can be globose, elliptical or oval, and the surface can be smooth or finely rough. The color of conidia determines the color of the conidial head which also determine the color of the colony [7].

\begin{tabular}{|c|c|}
\hline Kingdom & Fungi \\
\hline Division & Ascomycota \\
\hline Class & Eurotiomycetes \\
\hline Order & Eurotiales \\
\hline Family & Trichocomaceae \\
\hline Genus & Aspergillus \\
\hline
\end{tabular}

Source: [5]

Table 1: Taxonomy of Aspergillus.

*Corresponding author: Mebrie Zemene, Lecturer, Faculty of Veterinary Medicine Department of Veterinary Pharmacy, University of Gondar, Gondar, Ethiopia, Tel: 251918518866; E-mail: zemenemebrie@gmail.com

Received July 12, 2016; Accepted August 31, 2016; Published September 05, 2016

Citation: Girma G, Abebaw M, Zemene M, Mamuye Y, Getaneh G (2016) A Review on Aspergillosis in Poultry. J Vet Sci Technol 7: 382. doi: 10.4172/21577579.1000382

Copyright: @ 2016 Girma G, et al. This is an open-access article distributed under the terms of the Creative Commons Attribution License, which permits unrestricted use, distribution, and reproduction in any medium, provided the original author and source are credited. 


\section{Epidemiology}

Aspergillus spp are ubiquitous and the disease has a worldwide distribution and may be found whereever environmental condition is favorable for fungal growth. These organisms are common soil saprophytes and grow on organic matter in warm $\left(>25^{\circ} \mathrm{C}\right)$ humid environments including damaged egg in hatcheries and poor ventilation system. The disease more frequently occurs in tropical countries like Ethiopia. Sever outbreak associated with hatchery contamination may result in up to $15 \%$ chicken mortality during the first two weeks and decrease growth rate on affected survivors [2].

Concerning the distribution of Aspergillosis among different seasons, [8] reported that the disease is prevailing throughout the year but in hot and humid weather condition, the percentage of positive isolates in both lung and environmental samples was higher in summer (50\% and $41.2 \%$ ) respectively, followed by winter season which was $(29.2 \%$ and $29.4 \%)$ respectively as compared with other seasons of the year. These are because of the warm, humid environment and the disease in winter season is common when indoor gas levels tend to be highest.

\section{Transmision and predisposing factors}

Aspergillosis affects avian spp, other animals and humans. All birds are susceptible to aspergillosis. It is reported in domestic birds like poultry, duck, and quails as well as in wild bird [2]. Inhalation of conidia or spores from contaminated feed, fecal material, soil and contamination of egg in ovo, infect the developing embryo. Higher susceptibility of birds to aspergillosis may be attributed to anatomic and physiologic characteristics of the avian respiratory system. The small non-expanding lungs and nine air sacs constitute a primary nidus for infection because the air (or conidia) reaches the caudal air sacs before it pass through those part of the lungs in which the gas exchange takes place [9]. Higher body temperature also allows quick fungal growth. Other factors include chronic stress, unsanitary conditions, overcrowding, malnutrition, vitamin deficiencies especially vitamin A and overuse of certain medications (corticosteroids) as well as respiratory irritants (disinfectant fumes and aerosol sprays). Birds that are otherwise ill or are very young or old are also susceptible to aspergillosis [10]. The incidence of aspergillosis increased when chicken reared on saw dust than rice husk as litter and incidence was $67.74 \%$ and $32.26 \%$ respectively might be due to high moisture content of saw dust allowing more fungal growth than rice husk [11].

\section{Pathogenesis}

Aspergillosis is caused by inhalation of overwhelming numbers of small, hydrophobic fungal spores (conidia) into the respiratory tract. After infective spores invade tracheal, nasal, bronchial and air sac epithelium, they penetrate the respiratory tissue and reproduce by single division of tubular hyphae to form mycelia and they initiate granulomas at this site. Then they are disseminated hematogeneously to the other tissue like brain, pericardium, bone marrow, kidney and other soft tissue. Tissue invasion creates an inflammatory condition and inflammatory response with hetrophils, lymphocytes, monocytes and some giant cells infiltrating the lesion and produce lesion [12]. Chronic disease especially in turkey often terminate in impendence of pulmonary blood flow caused by enlarging pulmonary granulomas and this cause right ventricular dilatation and ascitis. Another mortality cause for aspergillosis included exudates to become lodged in the trachea or syrinx producing acute respiratory embarrassment in chronically infected individuals [13].

\section{Clinical sign}

Aspergillosis may involve many body systems; fungal spores most commonly invade trachea, air sacs and lung. Signs depend on the number of spore that enter the body and organ system affected but can be generally reflected as disease of respiratory tract, occasionally the CNS [7]. There are three common presentation of the disease; diffuse lower respiratory tract diseases, syringeal graunloma and focal CNS graunuloma particularly in the brain [13].

Within the first 3-5 days newly hatched chicken infected in the hatchery show a very rapid and difficult breathing and start breathing with an open mouth (gaspers) due to the gradual obstruction of the air passage [14]. Survivor may become dull and stunted, show sleepiness, lack of appetite, emaciation, increased thirst, develop eye swelling or blindness and show torticolis (twisting of the neck to one side). Other birds may remain subclinically affected for some times but later slowly develop breathing problems. This is because increasing body weight put demands on the reduced functional capacity of the lung [15]

Infected poultry usually show mortality in two phases: Acute respiratory disease may cause $5-50 \%$ mortality in the first $1-3$ weeks of age. Those which survive usually develop chronic disease with up to $5 \%$ mortality due to pulmonary insufficiency, ascitis, blindness or neurological fungal metastasis. A common feature of dyspnea associated with aspergillosis is the lack of respiratory noise [15] (Figure 1).

\section{Necropsy finding}

The primary location of lesions is the lungs and air sacs although other organs may be involved. Extensive involvement of the respiratory tract can occur before development of clinical signs. Lesions vary in size from pinhead or miller seed (milliary $<1 \mathrm{~mm}$ in diameter) white to yellowish granulomas up to the size of a pea. Roughly spherical granulomatous nodules $(>2 \mathrm{~cm})$ may also be observed in serosa and parenchyma of the other organs involved [16].

Pulmonary lesions are characterized by multiple hard creams to yellow colored, circumscribe plaques a few $\mathrm{mm}$ to several $\mathrm{cm}$ in diameter seen throughout the lungs surface, inside the lungs, scattered in ventral surface of sternum and air passages on gross examination (Figures $2 \mathrm{a}$ and $2 \mathrm{~b}$ ). The plaques also found in the syrinx, air sacs,

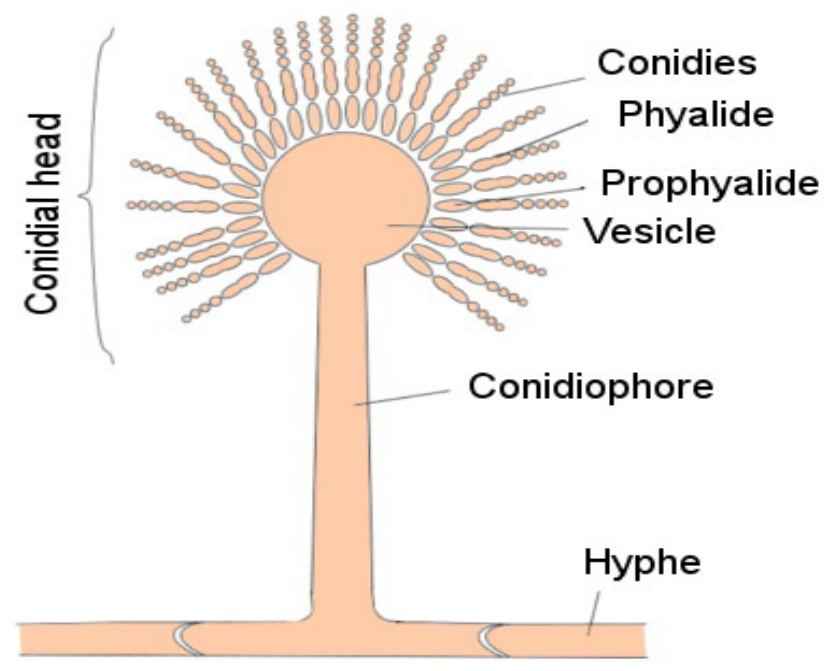

Figure 1: Structure of Aspergillus [5]. 

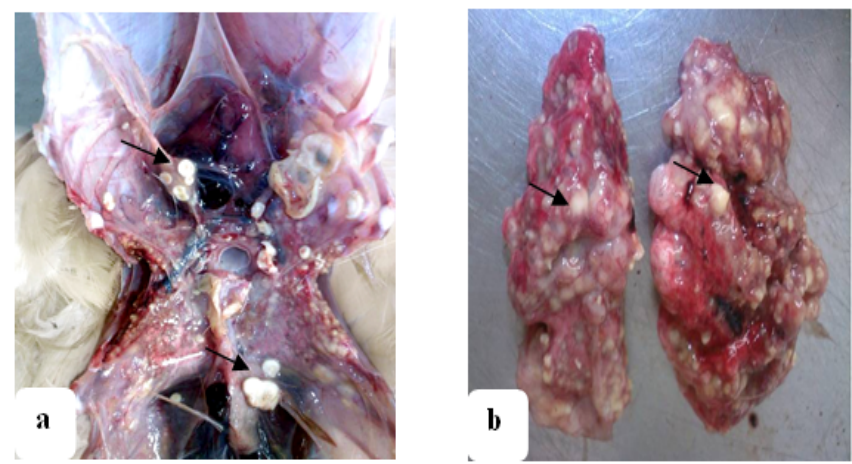

Figure 2: a. Lung shows the presence of cream color nodules in plural surface, air sacs (arrow). b. Creamy to yellow color nodules shows throughout the lung (arrow) [11].

liver and intestines. Lung parenchyma wasconsolidated and single or multiple necrotic areas are visible on cut surfaces of lungs [11].

Mycotic pododermatitis along with pulmonary aspergillosis was reported in turkeys. In footpads, keratinized epidermal disruption, encrustations and acute inflammation were noted [17]. Epidermal cysts associated with $A$. fumigatus have been described in the comb of a silky bantam chicken [18]. It leads to periorbital swelling, swollen and adhered eyelids with turbid discharge, cloudy cornea and cheesy yellow exudates within the conjunctival sac [19]. Osteo-arthritis and granulomatous osteoarthritis of the hip joints with necrosis of the femur head was observed in turkey [20].

Visceral organs were involved in aspergillosis with formation of nodular granulomatous lesions. Right ventricular dilatation or cor pulmonale due to pulmonary hypertension may occur with or without ascites in poultry [21]. Abscesses in the cerebellum and cerebrum were reported. It may occur with or without pulmonary and other lesions. In the cerebellum of broiler breeders and turkeys, circumscribed white to greyish areas were observed. Granuloma formation was also seen in the brain and lungs of layer chicken [22].

\section{Histopathology}

The microscopical examination showed congestion of pulmonary and perialveolar blood vessel and perivascular edema (Figure 3). The normal architecture of the lung and air sacs were replaced by disseminated granulomatous foci. The center of the granulomatous foci contained caseous necrosis and necrotic cellular debris surrounded by rims of heterophils, lymphocytes, macrophages and multinucleated giant cells was seen (Figure 3 ). The nodules consisted of coagulative necrotic center (Figure 4). A few, more severe, densification and inflammatory lesions were focally present on the pleura and the underlying pulmonary lobules (Figure 4) [11].

\section{Diagnosis}

Signs of aspergillosis are non-specific and making diagnosis is difficult. Moreover, no single test provides certainty. Diagnosis usually relay upon an accumulation of evidence from history, clinical presentation, postmortem findings, hematology, biochemistry, serology, radiographic changes, endoscopy, and culture of the fungus. Cases of aspergillosis in birds are often diagnosed based on postmortem findings of white caseous nodules in the lungs or air sacs of affected birds since clinical diagnosis is difficult [23]. The history of the bird can reveal a stressful event and some under lining environmental factors and immune suppressive condition or treatment. It may also reveal chronic debilitating, voice change or exercise intolerance [24]. Granulomatous nodules and /or cheesy plaques on the serosa and parenchyma of respiratory tracts as well as other organs are observed. But, definitive diagnosis is based on the isolation of Aspergillus species by culture or by the detection of the organism during histological examination [25]. Identification can also be made by preparing a wet smear. For this, a nodule can be dissected out and crushed on a slide beneath a cover slip in a drop of $20 \%$ potassium hydroxide and lactophenol cotton blue. The lactophenol cotton blue stains the fungal hyphae. Wet mounts can also be prepared from sputum or nasal swabs in either $10 \% \mathrm{KOH}$ and Calcofluor or Parker inkand/or Gram stain [26].

The tissue samples (lungs, trachea, pharynx and thoracic air sacs as well as other organs) fixed in $10 \%$ neutral buffered formalin are processed and embedded in paraffin blocks and stain with haematoxylin and eosin (HE) method. Aspergillus hyphae stained poorly in $\mathrm{H}$ and E stained sections. Differential stains such as Periodic acid-Schiff (PAS), Bauer's and Gridley's stains differentiate and easily identify the hyphae and mycelia. Special stains for fungus Grocott's and Gomori Methanamine Silver stain should be employed to detect the presence of fungal hyphae. For proper identification of the species, the pathogenic organism must be isolated by culturing it on differential media. Small pieces of lesions aseptically removed are placed onto plates or slants containing malt agar, Sabouraud's glucose agar or antibiotics and incubated at $37^{\circ} \mathrm{C}$ for 24 hours. Species of Aspergillus can be identified by observing the characteristic conidial head and colony [16].

\section{Differential Diagnosis}

The differential diagnosis includes infectious bronchitis (dyspnea), newcastle disease (watery greenish diarrhea), infectious larngeo tracheaties (gasping, cough and extension of the neck during inspiration), dactylaria infection (nervous sign) and nutritional encephalomalacia [27].
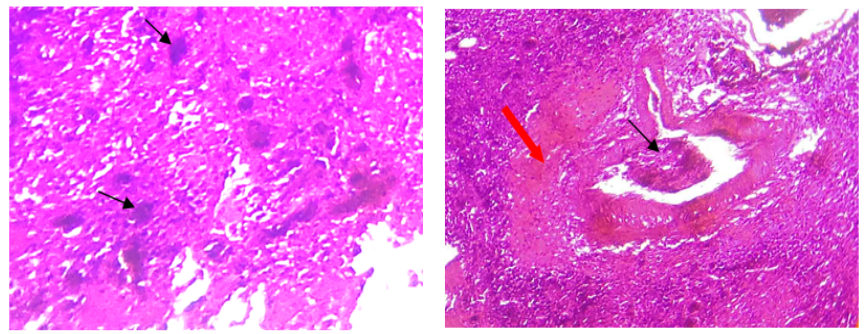

Figure 3: a. Showing congestion of pulmonary, perialveolar blood vessel and diffuse edema of pulmonary tissues (arrow) in Lung. b. Areas of caseous necrosis (black arrow) and cellular debris (red arrow) in lung [11].
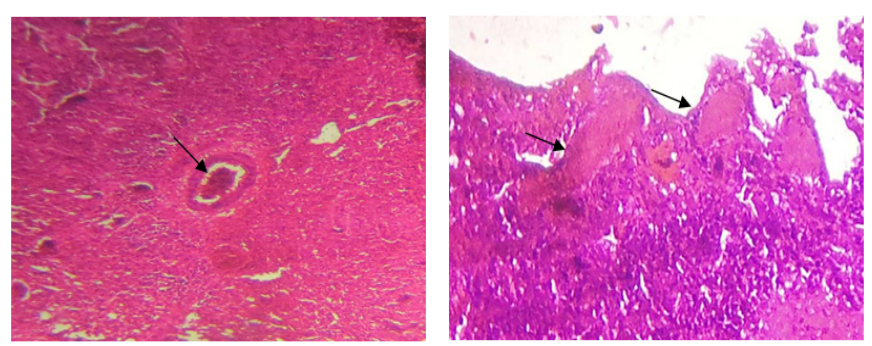

Figure 4: Aspergillosis showing granuloma formation with caseated center (arrow) in lung. b. Diffuse densification of the pleural parenchyma by congestion and an inflammatory cellular infiltration (arrows) in lung [11]. 


\section{Treatment}

Treatment for Aspergillosis is not effective because the drug used does not reach the fungus that is walled off by the bird's inflammatory response and therefore, isolated from the blood stream. This disease has a poor prognosis when the infection in the tissue is extensive and only systemic drugs are used. The best treatment results if the granulomatuos lesion is dried and topical treatment in conjunction with systematic therapy is given. Treatment of aspergillosis involves the use of one or more systemic antifungal agent. Drugs which are commonly used include itraconazole, ketoconazole, clotrimazole, miconazole, fluconazole and Amphotercin B. From these drugs, itraconazole is a choice of treatment of the disease [11].

\section{Prevention and control}

Aspergillosis has no effective treatment and prevention by vaccination is not commercially practicable. Therefore, control depends on reducing exposure to the fungus and associated risk factors. Aspergillus fumigatus in young chicken has been somewhat controlled by hatchery sanitation. Moldy litter or feed should be avoided to prevent outbreak of aspergillosis. It is advisable to treat poultry house and litter with antifungal compounds [28]. Any moldy feed should be removed, bulk feed container should be cleaned, old litter should be removed from house and replaced with new. Hatching equipment and air ducts should be cleaned, disinfected and well monitored. Contaminated hatchery should be fumigated with formaldehyde or thiabendazole $120-360 \mathrm{~g} / \mathrm{m}^{3}$ [13].

\section{Public Health Significance of Aspergillosis}

Aspergillosis has a zoonotic importance and recent outbreak of aspergillosis in chicken have left the chicken consuming population shocked and frightened. Aspergillosis is transmitted to man by handling infected birds and animals, inhalation of spores from infected feed and litter, poor sanitation and poor hygienic condition and by eating under cooked contaminated poultry [29]. Most mycotoxins produced by aspergillus are not broken down by cooking temperature and there is no safe way to salvage grain or food that has been molded. It is transmitted via inhalation or ingestion [2].

Three disease states are observed in man and these are: first; Infection that can arise from weakening effect of aspergillosis, for example colonization of the lung cavities due to tuberculosis, neoplasm or new growth in the lung or kidney almost in organ system in human body may be involved. Onychomycosis, sinusitis, cerebral aspergillosis, pulmonary aspergillosis, cutaneous aspergillosis, hepatic aspergillosis as well as disseminated aspergillosis may develop. Nosocomial occurrence of aspergillosis due to catheters and other devices is also likely to occur in hospital environment and is a major risk for the development of Aspergillosis particularly neuropenic patients. Second; Allergic reaction to Aspergillus spp, for example allergic bronchopulmonary aspergillosis (ABPA). Third; toxic reactions occur as result of toxin produced by Aspergillus spp. Aflatoxins which are carcinogenic, induce hepatocellular carcinoma or liver cancer [10].

Aspergillosis establishes itself in patients debilitating by chronic disease such as diabetes, cancer, tuberculosis and disease of immune system, as well as in person treated with antibiotics, anti metabolites, and corticosteroids for prolonged period [30]. Persons occupationally exposed for long periods to materials contaminated by fungus spores (grain, hay, cotton, wool and other) run a greater risk. Normal children who inhale large number of conidia may develop fever and dyspnea. Allergic bronchopulmonary aspergillosis (ABPA) occurs in patients with pre-existing asthma who present eosinophlia and intermittent bronchial obstruction [31-34].

\section{Conclusion and Recommendations}

Aspergillosis is a disease of respiratory system of chicken, humans, mammals and wild birds and caused by genus Aspergillus, which is distributed worldwide and it is soil saprophyte. It is a common mismanagement problem and causes a high mortality in chicken. Environmental factors play an important role in the development of the disease include the number of spores to which the bird exposed, poor sanitation in the house as well as food contaminated with faces promote for fungal growth. Poor ventilation in conjunction with other factor increases the possibility of occurrence of the infection. There is no effective treatment for the disease.

Based on the above conclusion, the following recommendations are forwarded:

- Cleaning and disinfection of feed and water utensils

- Poultry house must be well ventilated.

- Avoid overcrowding in poultry house.

- Avoid moldy or dusty feed.

- Proper Sanitation of hatching equipment.

- Treat poultry house and disinfect the litter with antifungal compound.

- Cull infected birds to prevent further contamination.

Use mold inhibitor in the feed for suspected outbreak.

\section{References}

1. Saif YM, Fadly AM, Glisson JR, McDougald LR, Nolan LK, et al. (1999) Disease of poultry. 12th edn. lowa State University Press, Ames, London, pp: 542-550.

2. Jordan F, Pattisson M, Alexander D, Faragher T (2002) Poultry Disease. 5th edn. Elsevier Limited, Saunders, UK, pp: 387-390.

3. Bauk L (1994) Mycosis. In: Avian medicine principle and application. Ritchie BW, Harrison GJ, Harrison LR (eds). Wingers Publishing Inc., Lake Worth, USA, pp: $174-180$

4. Richard JL, Calnk BW (1997) Aspergillosis and disease of poultry. 10th edn lowa State University Press, Ames, London, pp: 125-130.

5. Kearns KS, Loudis B (2003) Recent advances in avian infectious agent.

6. Shane SM (2005) Handbook on Poultry Diseases. 2nd edn. American Soybean Association, USA.

7. Atlaman RB (1997) Avian Medicine and Surgery. Saunders, Philadelphia, USA pp: 89-92.

8. Lobna MA, Salem AAF (2014) Epidemiological study of Aspergillosis in chickens and human contacts in chicken farms at Kalyoubia Governorate. IOSR Journal of Agriculture and Veterinary Science (IOSR-JAVS) 7: 20-24.

9. Nardoni S, Ceccherelli R, Rossi G, Mancianti F (2006) Aspergillosis in Larus cachinnans micaellis: survey of eight cases. Mycopathologia 161: 317-321.

10. Coles BY (1997) Avian Medicine and Surgery. 2nd edn. Blackwell Science, London, pp: 333-340.

11. Sultana S, Rashid SMH, Islam MN, Ali MH, Islam MM, et al. (2015) Pathological Investigation of Avian Aspergillosis in Commercial Broiler Chicken at Chittagong District. International Journal of Innovation and Applied Studies 10: 366-376.

12. Kunkle RA, Rimiler RB (1996) Pathology of Acute Aspergillosis in Turkeys. Avian Dis 40: 875-886.

13. Pattisson M, McMullin P, Bradbury J, Alexander D, Jordan F (2008) Poultry disease. 6th edn. Elsevier Limited, Saunders, UK, pp: 428-431. 
Citation: Girma G, Abebaw M, Zemene M, Mamuye Y, Getaneh G (2016) A Review on Aspergillosis in Poultry. J Vet Sci Technol 7: 382. doi: $10.4172 / 2157-7579.1000382$

Page 5 of 5

14. Aguilar RF, Redig PT (1995) Diagnosis and treatment of avian aspergillosis Current Veterinary Therapy XII. Philadelphia, PA: WB Saunders, pp: 1294-1299.

15. Vegad JL (2008) Poultry diseases: a guide for farmers and poultry professionals. 2nd edn. International Book Distributing Co., India, pp: 179-181.

16. Fowler ME (1993) Zoo \& Wild Animal Medicine Current Therapy. Volume 3. WB Saunders \& Co., Philadelphia: USA, pp: 178-181.

17. Cannon M (1999) Aspergillosis in poultry. J Med Surg Aquat Birds 327: 527-568.

18. Curities $P$ (1990) A hand book of poultry and game birds. 4th edn. Blackwell Publishing, London, pp: 123-130.

19. Leishangthem GD, Singh ND, Brar RS, Banga HS (2015) Aspergillosis in Avian Species: A Review. J Poult Sci 3: 01-14.

20. Stoute ST, Bickford AA, Walker RL, Charlton BR (2009) Mycotic pododermatitis and mycotic pneumonia in commercial turkey poults in northern California. J Vet Diagn Invest 21: 554-557.

21. Suedmeyer WK, Bermudez AJ, Fales WH (2002) Treatment of epidermal cysts associated with Aspergillus fumigatus and Alternaria species in a silky bantam chicken. J Avian Med Surg 16: 133-137.

22. Hoppes S, Gurfield N, Flammer K, Colitz C, Fisher P (2000) Mycotic keratitis in a blue-fronted Amazon parrot (Amazona aestiva). J Avian Med Surg 14: 185-189.

23. Olias P, Hauck R, Windhaus $H$, van der Grinten E, Gruber AD, et al. (2010) Articular aspergillosis of hip joints in turkeys. Avian Dis 54: 1098-1101.

24. Höfle U, Blanco JM, RodriguezA, Vicente A(2001)Atypic aspergillosis ${ }^{\star}$ a new threat to the Iberian imperial eagle (Aquila adalberti). In: Korbel $R$ (ed.), Proceedings of the German Veterinary Medical Society, 6th European AAV-DVG Conference of the Association of Avian Veterinarians, 4th Scientific ECAMS Meeting of the European College of Avian Medicine and Surgery, p: 288.
25. Kim JY, Kim JM, Mo IP (2011) Multisystemic Aspergillosis with Granulomas in Layer Chickens. Korean J Poult Sci 38: 45-50.

26. Charlton BR, Chin RP, Barnes HJ (2008) Fungal infections. In: Diseases of Poultry. Saif YM, Fadly AM, Glisson JR, McDougald LR, Nolan LK, et al. (eds.). lowa State University Press, Ames, lowa, USA, Chapter 9, pp: 989-998.

27. Olgebsee BL, Altaman RB, Clubb SL (1997) Avian medicine and surgery Philadelphia Saunders, USA, pp: 564-570.

28. Kunkle RA (2003) Aspergillosis. In: Diseases of Poultry. Saif YM, Fadly AM, Glisson JR, McDougald LR, Nolan LK, et al. (eds.). lowa State University Press, Ames, lowa, USA, pp: 883-895.

29. Horrer FJ, Clank BW (1997) Poisons and toxins. Disease of poultry. 10th edn.

30. Kahn CM (2010) The Merk Veterinary Manual. 9th edn. Merck and Co., Inc. White House Station, NJ, USA, pp: 654-660.

31. Jones MP, Orosz SE, Cox SK, Fraizier DL (2000) Pharmacokinetic Disposition of Itraconazole in Red-Tailed Hawks (Buteo jamaicensis). Avian Med Surg 14: $15-22$.

32. Abrams GA, Paul-Murphy J, Ramer JC, Murphy CJ (2001) Aspergillus blepharitis and dermatitis in a peregrine falcon-gyrfalcon hybrid (Falco peregrinus $\times$ Falco rusticolus). J Avian Med Surg 15: 114-120.

33. Ivey ES (2000) Serologic and Plasma Protein Electrophoretic Findings in 7 Psittacine Birds with Aspergillosis. J Avian Med Surg 14: 103-106.

34. Pedon N, Boris SF (2003) Zoonosis and communicable disease common to man and animals. 3rd edn. Washington, DC, PAHO. pp: 305-310. 